\title{
THIN-FILM SILICON IN PHOTOVOLTAICS: THE ROLE OF STRUCTURE AND MICROSTRUCTURE
}

Structure and microstructure of hydrogenated silicon thin films and the influence of the hydrogen dilution of silane plasma at the PEVCD deposition on the film properties were investigated. The results show that at dilution between 20 and 30 the transition between amorphous and crystalline phase occurs. The sample becomes a mixture of amorphous silicon, polycrystalline silicon with nano-sized grains and voids with decreasing hydrogen concentration at grain boundaries and post-deposition oxygen contamination. The dominance of Si-H bonds and presence of interstitial oxygen and oxygen bonded in surface Si-OH groups was observed.

\section{Introduction}

Solar cells convert solar energy into electricity - either directly through the photovoltaic effect (photovoltaic cells or PV cells) or via a two-step process converting solar energy first into heat or chemical energy. The PV industry and market progress rapidly owing to the global energy consumption demands, the need for renewable and sustainable power, as well as owing to the reducing technological costs. Growing PV market reflects the world-wide needs for non-polluting long-lasting electricity sources for remote devices, e.g. satellites, remote places, e.g. remote settlements, campers or small devices of everyday use, e.g. watches, calculators, cameras etc.

The main criteria to select the beneficial cell material are efficiency, stability and costs. Definitely the most used material in photovoltaics is silicon. Silicon PV industry takes advantage of material abundance, non-toxicity, and the possibility to share research efforts with microelectronic industry. Silicon in PV cells is used as:

- monocrystalline silicon (mc-Si) and polycrystalline silicon (polySi, polysilicon) - the cells are the most effective Si-based solar cells, however, they need expensive wafer-based production technologies suffering from substantial waste of material,

- amorphous silicon (a-Si) in the thin-films configuration - the cells are produced by the module-based technology, essential layers are deposited on the substrate mostly by the conventional chemical vapour deposition (CVD), mainly by plasma-enhanced CVD (PECVD) or hot-wire assisted CVD. Thin film technologies allow reducing the amount of silicon used and using the material of poorer quality and hence reduce costs per watt of power output.

Today, the vast majority of PV market is based on crystalline silicon. The conversion efficiencies of a-Si based thin-film cells and panels are lower in comparison with mc-Si and poly-Si cells. However, they take advantage of reduced production costs, and therefore they still attract a lot of attention of researchers and producers in the PV competition with conventional sources of electricity.

Amorphous silicon is characterised by higher absorption of light than c-Si and allows the deposition on low-cost substrates (glass, metals, plastics) at low temperatures $\left(<250^{\circ} \mathrm{C}\right)$. Differently from c-Si, the loss of structure order in a-Si results in defects (dangling bonds and distorted Si-Si bonds in both lengths and angles). Defects bring about energy levels in the energy gap where charge carriers recombine and limit the photocurrent. It was discovered that in a-Si deposited under hydrogenation conditions like PECVD and hot-wire CVD using the silane $\left(\mathrm{SiH}_{4}\right)$ precursor, hydrogen atoms saturate dangling bonds and weak bonds thus remove defects and result in a defect-free energy gap. CVD deposition techniques allow depositing hydrogenated amorphous silicon (a-Si:H) thin films with tailored structure and physical properties for photovoltaics and optoelectronics $[1,2,3]$.

Nevertheless a-Si:H solar cells suffer from light-induced metastability - the Staebler-Wronski effect discovered in 1977 [4]. The microscopic origin of this photodegradation is still under extensive studies. The so-called protocrystalline or edge $\mathrm{Si}$, i.e. amorphous Si near and above the onset of microcrystallinity prepared by CVD under additional amount of hydrogen - the so-called hydrogen dilution of silane plasma - attracts attention. $\mathrm{H}_{2}$ dilution of $\mathrm{SiH}_{4}$ is the gas flow ratio $D=\left[\mathrm{H}_{2}\right] /\left[\mathrm{SiH}_{4}\right]$ and results in films with higher stability. The hydrogen-dilution PECVD improves both material and solar cell stability. Therefore, solar cells photodegrade less than other samples prepared by other methods and thicker layers can be deposited at reduced deposition rates. Structure of small crystallites of $10 \sim 100 \mathrm{~nm}$ embedded in a-Si network and mostly terminated by hydrogen is observed. This structure makes

\footnotetext{
* J. Müllerová ${ }^{1}$, P. Šutta ${ }^{2}$, S. Jurečka ${ }^{1}$

${ }^{1}$ Department of Engineering Fundamentals, Faculty of Electrical Engineering, University of Žilina, ul.kpt. J. Nálepku 1390, 03101 Liptovský Mikuláš, Slovakia

${ }^{2}$ University of West Bohemia, New Technologies - Research Centre, Univerzitní 8, 30614 Plzeň, the Czech Republic

E-mail: mullerova@lm.utc.sk
} 
defect density lower and reduces recombination of photo-excited carriers.

The formation of microcrystalline boundary feels the deposition conditions, substrate material and film thickness. One of the up-to-now rare theoretical models of hydrogen-induced phase transition shows [5] that the crystallisation is due to the chemical rearrangement of a-Si:H network under additional hydrogen. Physical and technological aspects of the transition from amorphous to polycrystalline silicon are of great importance. As material properties are strongly dependent on exact deposition conditions, deposition parameters (e.g. substrate temperature, rf power, excitation frequency) can be set to favour the crystallisation.

This work reports on experimental studies of the structure, hydrogen and oxygen microstructure of a-Si:H thin films deposited by PECVD on glass from hydrogen diluted silane plasma.

\section{Experimental}

Undoped Si:H thin films were deposited at the Delft University of Technology, the Netherlands, on clean Corning 1737 glass substrates by $13.5 \mathrm{MHz}$ rf excited parallel plate PECVD industrial deposition system [6] (rf power 13.5 W). The deposition was performed at the substrate temperature $194{ }^{\circ} \mathrm{C}$ and the total chamber pressure $200 \mathrm{~Pa}$ from hydrogen to silane plasma under varying dilution $D$. A series of 6 samples was investigated (Table 1). The thickness of the samples was kept at approximately the same value $\sim 400 \mathrm{~nm}$ to avoid the thickness influence on the film properties.

The surface and cross-section morphology were inspected by AFM - atomic force microscopy (NT-MDT SPM Solver P7 LS in the contact repulsive mode) and SEM - scanning electron microscopy (QUANTA 200). Structure analysis was investigated by X-ray diffractometry (X-ray diffractometer Bruker AXS D8 with a 2D detector using $\mathrm{CoK} \alpha$ radiation), Raman scattering (488 $\mathrm{nm} \mathrm{Ar}^{+}$ laser [7]) and FTIR - Fourier transform infrared spectroscopy (DIGILAB FTS 3000MX Excalibur spectrophotometer in the horizontal attenuated total reflection mode).

\section{Results and discussion}

\section{Structure and surface morphology}

According to the Raman spectra (Fig. 1), the samples deposited at $D \geq 30$ are mixed phase material. The lattice expansion and finite dimensions of the crystallites in the films manifest themselves in Raman components - one of the peak intensity $I_{520}$ close to the wavenumber $\bar{v}=520 \mathrm{~cm}^{-1}$ belonging to crystalline $\mathrm{Si}$, another of the peak intensity $I_{480}$ at $480 \mathrm{~cm}^{-1}$ belonging to amorphous Si. The ratio $x_{c}=\frac{I_{520}}{I_{520}+I_{480}}$ is considered as the degree of crystallinity. The degree of crystallinity increases with increasing dilution (Table 1). From the shift of the Raman peak at $520 \mathrm{~cm}^{-1}$ by the procedure described in [8], the grain size can be calculated. The grain size is $L_{R}=\sqrt{\frac{88.43}{|\Delta \bar{v}|}}$ where the Raman peak shift position is $\Delta \bar{v}=\bar{v}-520.7 \mathrm{~cm}^{-1}$ (Table 1). Tensile stress leads to the Raman peak shift to smaller wavenumbers and higher stress causes a higher peak shift. Thus, crystallisation induces tensions in the samples under study.

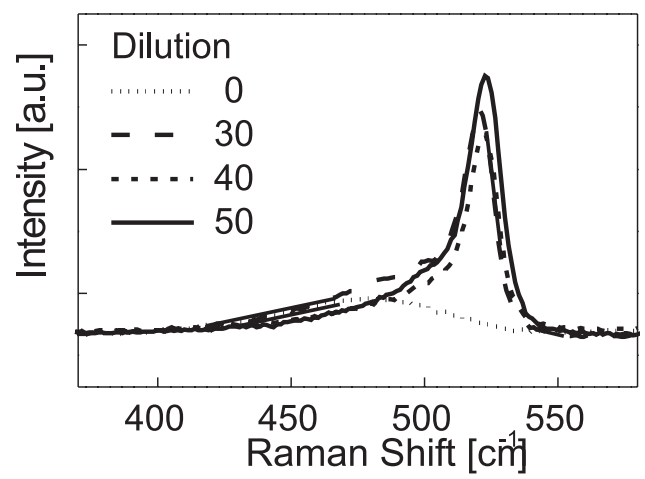

Fig. 1 Raman spectra of the undiluted sample and the samples deposited under higher dilution.

X-ray diffraction (XRD) data provide the same observation of the progressive formation of crystalline $\mathrm{Si}$ with increasing $D$ as Raman spectra. In the XRD patterns of the first three samples at $D<30$ no diffraction lines of crystalline Si are present. We conclude that the samples are either amorphous or with negligible part of the crystalline phase. The XRD scans of the samples at $D \geq 30$ in Fig. 2 show three diffraction lines ascribed to (111), (220), and (311) of crystalline silicon. This suggests that the films become polycrystalline. For the comparison the XRD scan of the amorphous glass substrate is added to the plots in Fig. 2.

From the broadening of diffraction lines the average microstrain (relative microdeformation) and the average size of the coherently diffracting domains were deduced by the procedures outlined in [9] (Table 2). The size of the coherently diffracting domains or simply the grain size is defined as the average size of crystallites perpendicular to the diffracting plane. For the calculations, ceramic $\mathrm{Al}_{2} \mathrm{O}_{3}$ from NIST (National Institute for Standards and Technology) was used as an instrumental standard. From the shift of the diffraction lines in consideration to the position of the standard diffraction lines, the biaxial lattice stress (so-called macrostress) was calculated. When the diffraction line shifts to the lower $2 \vartheta$ angle than that of the standard, the thin film is under tensile stress while the shift to the higher angle induces compressive stress. The X-ray diffraction analysis shows that all three mixed-phase films are primarily under tensile stress (Table 2).

AFM analysis of the sample frames $2 \times 2 \mu \mathrm{m}^{2}$ shows surface features appearing with increasing dilution as can be seen in the 3D AFM images (Fig. 2, 3 for the samples at $D=30$ and $D=50$ ). Vertical relief structure can be evaluated from AFM data by the 


\begin{tabular}{|c|c|c|c|c|c|c|}
\hline sample & $\begin{array}{c}\text { dilution } \\
D\end{array}$ & thickness $[\mathrm{nm}]$ & $\begin{array}{c}\text { rms roughness } \\
{[\mathrm{nm}]}\end{array}$ & $\begin{array}{c}\text { degree of } \\
\text { crystallinity [\%] }\end{array}$ & $\begin{array}{c}\text { peak shift } \\
{\left[\mathrm{cm}^{-1}\right]}\end{array}$ & $\begin{array}{c}\text { average grain size } \\
{[\mathrm{nm}]}\end{array}$ \\
\hline$\# 1$ & 0 & 390 & - & - & - & - \\
\hline$\# 2$ & 10 & 394 & 0.756 & - & - & - \\
\hline$\# 3$ & 20 & 385 & 1.013 & - & - & - \\
\hline$\# 4$ & 30 & 388 & 3.629 & 61 & 3.2 & 5.2 \\
\hline$\# 5$ & 40 & 402 & 5.476 & 73 & 1.9 & 6.8 \\
\hline$\# 6$ & 50 & 397 & 5.021 & 82 & 1.1 & 9.3 \\
\hline
\end{tabular}

Residual stress - macrostress and microstrain.

Table 2

\begin{tabular}{|c|c|c|c|c|c|c|}
\hline sample & $\begin{array}{c}\text { dilution } \\
\quad D\end{array}$ & \multicolumn{3}{|c|}{$\begin{array}{l}\text { diffraction line position } \\
{[\text { deg] }}\end{array}$} & $\begin{array}{c}\text { grain size } \\
{[\mathrm{nm}]}\end{array}$ & $\begin{array}{l}\text { average } \\
\text { microstrain }\end{array}$ \\
\hline$\# 4$ & 30 & 33.73 & 55.88 & 66.23 & $10 \pm 3$ & 0.02 \\
\hline \#5 & 40 & 34.16 & 56.09 & 66.19 & $10 \pm 3$ & 0.02 \\
\hline$\# 6$ & 50 & 33.63 & 55.81 & 66.25 & $40 \pm 5$ & 0.005 \\
\hline $\begin{array}{l}\text { Instrumental } \\
\text { standard }\end{array}$ & & 33.15 & 55.28 & 66.25 & & \\
\hline biaxial stress & & tensile & tensile & compressive & & \\
\hline
\end{tabular}

calculation of the rms roughness (Table 1) which shows the maximum at $\sim D=40$ at which the amorphous-to-crystalline transition may be accomplished. This increase may be connected with growing crystalline grains according to the geometrical model of conical microcrystalline conglomerates [1]. The thin film prepared under dilution $D$ between 20 and 30 may be considered as a film on the boundary between amorphous and crystalline phase. The lateral dimensions of the largest features are $\sim 200 \mathrm{~nm}$ for the film prepared at $D=30$. With $D$ increasing over this value the lateral size of grains decreases $(\sim 100 \mathrm{~nm}$ for the samples at $D=40, D=50$ ), they finally touch each other to form a smoother surface.

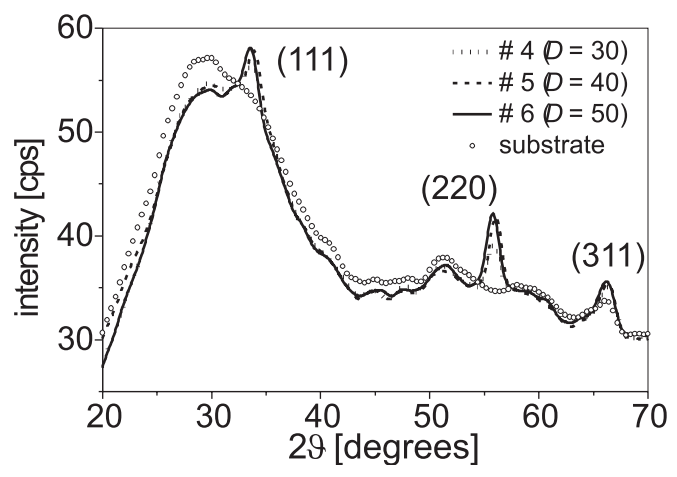

Fig. 2 XRD scans of the samples prepared at $D \geq 30$ and of the glass substrate.

The size of crystalline grains determined from the XRD analysis and from Raman spectra (Table 1, Table 2) is much smaller

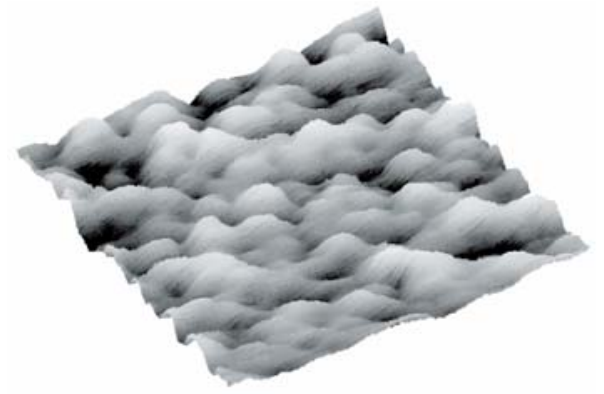

Fig. 3 AFM image of the $2 \times 2 \mu \mathrm{m}^{2}$ surface of the sample \# 4 (dilution 30).

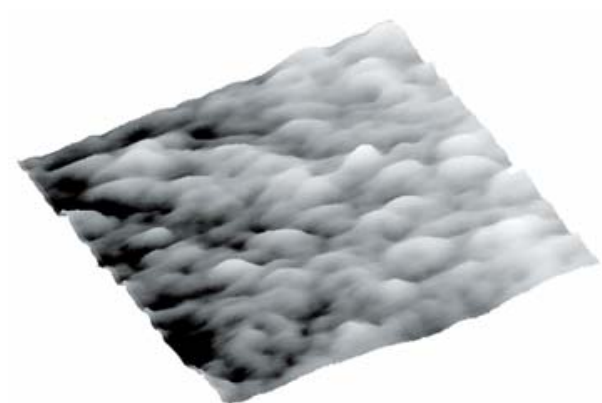

Fig. 4 AFM image of the $2 \times 2 \mu \mathrm{m}^{2}$ surface of the sample \# 6 (dilution 50).

than that of surface features inspected by AFM measurements. We conclude that features seen by AFM are polycrystalline aggregates of nano-sized crystalline grains for the samples prepared at $D \geq 30$. 
For the comparison we insert the SEM cross-sectional micrograph of the sample deposited at $D=50$ on crystalline (111) Si substrate (Fig.5). The sample has similar optical properties and structure as the sample \#6 on glass [3]. SEM image evidences compact film with high packing density of conical conglomerates and negligible porousity.

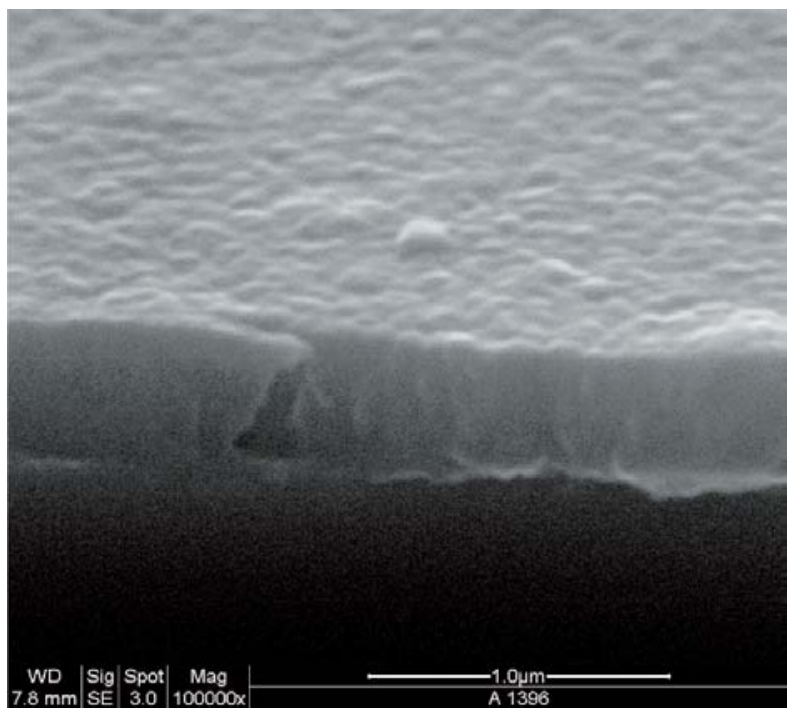

Fig.5 SEM cross-sectional micrograph of the almost fully crystallized polysilicon - sample deposited at the dilution 50 at $n^{+}$(111) $\mathrm{Si}$ substrate.

\section{Microstructure}

According to the structure analysis, the samples prepared at $D \geq 30$ are polysilicon composed of nano-sized grains and grain boundaries formed by amorphous Si, hydrogen and voids (Fig. 6).

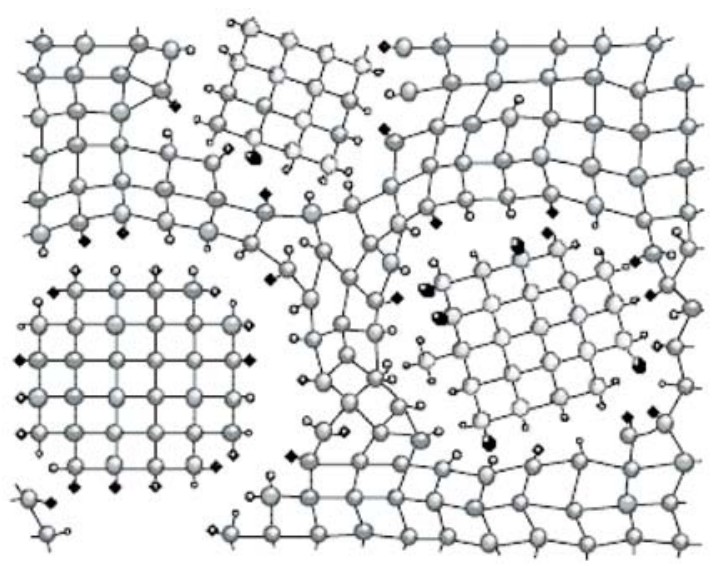

Fig.6 Mixed-phase hydrogenated Si. Crystalline grains of silicon (large circles) terminated by hydrogen (small circles) and embedded in the amorphous tissue.

(Drawing from National Institute of Advanced Industrial Science \& Technology Tsukuba, Japan).
FTIR absorbance spectra exhibit absorption peaks corresponding to $\mathrm{Si}: \mathrm{H}$ or $\mathrm{Si}-\mathrm{O}$ bonds and revealing the microstructure of hydrogen and oxygen in grains and at grain boundaries. The attention was focused on the broad absorbance band at wavenumbers $\bar{v} \sim 2000 \mathrm{~cm}^{-1}$, which is the convolution of predominant $\mathrm{Si}: \mathrm{H}$ stretching vibrations centered at $\sim 2000 \mathrm{~cm}^{-1}$ and $\mathrm{SiH}_{2}$ at $\sim 2090 \mathrm{~cm}^{-1}$. More loose $\mathrm{SiH}_{2}$ bonds are typical for polycrystalline silicon. Integral intensities of two deconvoluted peaks are proportional to bonded atoms densities.

Properties of polysilicon as a function of hydrogen microstructure are represented by the microstructure factor

$$
\mu=\frac{\int I_{\mathrm{SiH}_{2}}(\bar{v}) d \bar{v}}{\int I_{\mathrm{SiH}_{2}}(\bar{v}) d \bar{v}+\int I_{\mathrm{SiH}}(\bar{v}) d \bar{v}}
$$

which is commonly considered as a figure of merit of the quality of the films when being $<10 \%$ [10]. The concentration of $\mathrm{H}$ atoms bonded to Si is $N=A_{x} \int \frac{\alpha(\bar{v})}{\bar{v}} d \bar{v}$, where $A_{x}$ is the proportionality constant for specific vibrational mode [11], $\alpha(\bar{v})$ is the wavenumber-dependent absorption coefficient. Hydrogen concentration in atomic percent is

$$
C=\frac{A_{x}}{N_{\text {int }}} \int \frac{\alpha(\bar{v})}{\bar{v}} d \bar{v}
$$

$N_{\text {int }}$ is the total atomic concentration of the films $\left(5 \times 10^{22} \mathrm{~cm}^{-3}\right.$ for $\mathrm{c}-\mathrm{Si}$ ). The microstructure factor and hydrogen concentration (calculated with $A_{x}=9 \times 10^{19} \mathrm{~cm}^{-2}$ ) versus dilution are in Fig. 7 . Hydrogen concentration declines with increasing dilution and thus with progressing crystallization.

Nano-grains obviously attract air oxygen. Post-deposition oxygen contamination of Si:H films usually detrimentally results in conductivity changes and enhanced porosity of the samples [12]. FTIR measurements show that all films are contaminated with certain amount of oxygen. In the absorbance spectra the pronounced stretching vibrations of the interstitial oxygen in the O-Si-O bonds at $\sim 1000 \mathrm{~cm}^{-1}$ and about one order less intense surface vibrational features extended from $3000 \mathrm{~cm}^{-1}$ to $3800 \mathrm{~cm}^{-1}$ attributed to asymmetric streching vibrations of $\mathrm{Si}-\mathrm{OH}$ species are present. The area under the broad band of surface Si-OH groups called silanols at $\sim 3100 \mathrm{~cm}^{-1}$ is the oxygen-related parameter proportional to the surface oxygen density. It reaches its maximum at $D \sim 20$ and then decreases. The same behaviour attributed to interstitial oxygen was observed analysing the absorption band at $\sim 1000 \mathrm{~cm}^{-1}$ (Fig.8). In Fig. 8 one can also see the similar dilution dependence of the area under the absorption peaks at $\sim 850 \mathrm{~cm}^{-1}$ referred to the relatively weak bending vibrations of Si-H bonds. Patterned regions in Fig. 7 and Fig. 8 at $D \sim 20 \div 30$ indicate the protocrystalline material recommended for photovoltaic application. 


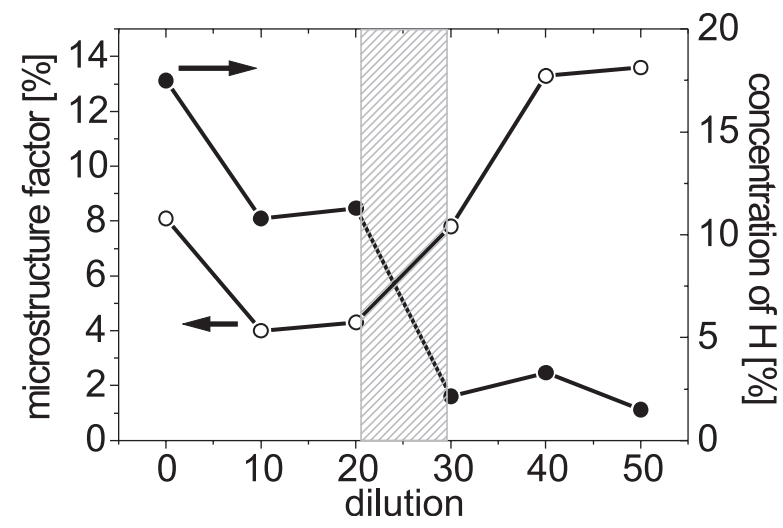

Fig. 7 Microstructure factor and the hydrogen concentration as the function of dilution.

\section{Conclusions}

In PECVD deposition of Si:H thin films for photovoltaic applications, remarkable changes in structure and microstructure due to the increasing hydrogen dilution were detected. The samples prepared at the dilution under 20 remain within the amorphous regime while the dilution over 30 favours the crystallisation and tensile stress. The films prepared at $D \geq 30$ were identified as polycrystalline Si. Grains in nanometer scale recognized by XRD analysis and Raman scattering exist within the features seen by AFM. The grain size increases with increasing dilution.

The protocrystalline regime recommended for photovoltaics occurs between dilutions 20 and 30 whilst other deposition parameters, esp. rf power, deposition temperature and the film thickness

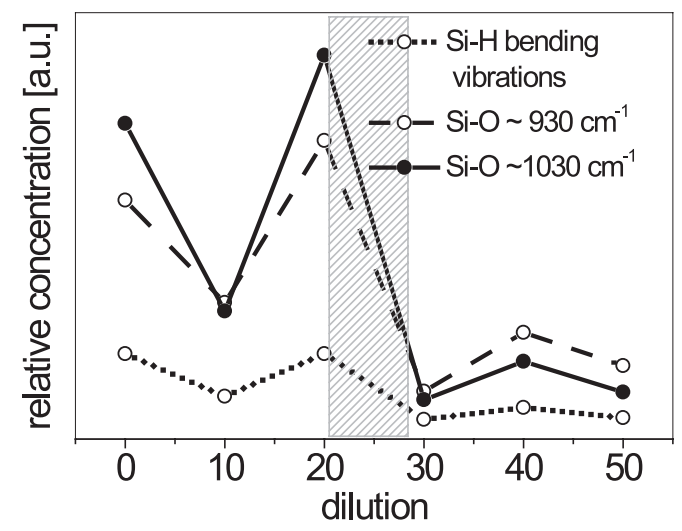

Fig.8 Relative concentrations of hydrogen and oxygen representing microstructure versus dilution.

are kept constant. FTIR spectroscopy reveals primarily monohydride $\mathrm{SiH}$ bonding with increasing part of dihydride $\mathrm{SiH}_{2}$ while the dilution rises. With increasing dilution and the crystallinity, the hydrogen concentration decrease. In spite of the microstructure factor being over $10 \%$ in polycrystalline films, the inevitable film porousity and increasing presence of oxygen were not observed.

\section{Acknowledgements}

This work was supported in part by the Slovak Grant Agency under grants No.2/4105/04, No. 2/4100/04 and by the Project of Research and Development LN00B084 of the Czech Ministry of Education, Youth and Sports. Dr Nádaždy at the Institute of Physics, Slovak Academy of Sciences, Bratislava, Slovakia, is acknowledged for the sample preparation.

\section{References}

[1] KOČKA, J., FEJFAR, A., MATES, T., FOJTÍK, P., DOHNALOVÁ, K., LUTEROVÁ, K., STUCHLÍK, J., STUCHLÍKOVÁ, H., PELANT, I., REZEK, B., STEMMER, A., ITO, M.: Phys. Stat. Sol. (c), 1, No.5, 1097, 2004.

[2] KOVAL, R. C., KOH, J., LU, Z., JIAO, L., COLLINS, R. W., WRONSKI, C. R.: Appl. Phys. Lett. 75, No.11, 1553, 1999.

[3] MÜLleroVÁ, J., JUREČKA, S., ŠUTTA, P.: Acta Physica Slovaca, 55, No. 3, 351, 2005.

[4] STAEBLER, D. L., WRONSKI, C. R.: Appl. Phys. Lett., 31, 292, 1977.

[5] SRIRAMAN, S., AGARWAL, S., AYDIL, E. S., MAROUDAS, D.: Nature 418, 62, 2002.

[6] NÁDAŽDY, V., DURNÝ, R., THURZO, I., PINČÍK, E., NISHIDA, A., SHIMIZU, J., KUMEDA, M., SHIMIZU, T.: Phys. Rev. $B$ 66, 195211, 2002.

[7] NÁDAŽDY, V.: Personal communication.

[8] PARK, Y.-B., LI, X., RHEE, S.-W., PARK, D.-W.: J. Appl. Phys. 90, 1, 219, 2001.

[9] VAN ZUTPHEN, A. J. M. M., ŠUTTA, P., TICHELAAR, F. D., VON KEITZ, A., ZEMAN, M., METSELAAR, J. W.: J. Crystal Growth, 223, 332, 2001.

[10] STANOWSKI, B., SCHROPP, R. E. I.: Thin Solid Films, 383, 125, 2001.

[11] PEREYRA, I., CARRENO, M.N.P., TABACSNIK, M. H., PRADO, R. J., FANTINI, M. C. A.: J. Appl. Phys., 84, 5, $2371,1998$.

[12] PERShEYEV, S. K., O’NEILl, K. A., ANTHONY, S., ROSE, M. J., SMIRNOV, V., REYNOLDS, S.: Mat. Res. Soc. Symp. Proc., 808, A9.10.1, 2004. 